\title{
APLIKASI PERPUSTAKAAN BERBASIS ONLINE SMK NEGERI 4 BANJARMASIN
}

\author{
Hoiriyah \\ Fakultas Teknologi Informasi \\ Universitas Islam Kalimantan Muhammad Arsyad Al Banjari Banjarmasin \\ ihaybjm18@gmail.com
}

\begin{abstract}
ABSTRAK
Pada perpustakan yang digunakan untuk pengolahan data anggota, data peminjaman dan pengembalian buku, perhitungan transaksi pembayaran denda keterlambatan pengembalian buku, pencarian buku yang dibutuhkan. masih dilakukan secara manual belum terkomputerisasi, Permasalahan yang sering dihadapi pada Perpustakaan adalah proses transaksi peminjaman buku karena menggunakan buku berupa data transaksi pinjam dan kembali, memperlambat proses pencarian berkas dan pembuatan laporan dalam perbulannya. Sehingga membutuhkan waktu extra, dan rumitnya dalam pembuatan laporan sehingga cukup menyita waktu, tenaga dan pikiran. Dengan di buatnya aplikasi tersebut dapat memaksimalkan permasalahan yang sebelumnya masih manual sekarang sudah terkomputerisasi dan dapat di akses secara online sehingga menyelesaikan permasalahan tersebut
\end{abstract}

Keyword : Sistem Informasi, Administrasi Perpustakaan, Database

\section{PENDAHULUAN}

\subsection{Latar Belakang Masalah}

Pengelolaan perpustakaan pada masa kini semakin menuntut kualitas dan profesionalisme agar hasilnya dapat dimanfaatkan semaksimal mungkin oleh penggunanya. Dengan perkembangan teknologi saat ini memang diperlukan suatu sistem informasi yang menangani administrasi perpustakaan. Sistem informasi tersebut berkaitan dengan pengelolaan data buku, pengelolaan data anggota, pengelolaan data sirkulasi peminjaman buku dan pengelolaan data administasi lainnya. Dengan adanya sistem informasi perpustakaan tersebut tentunya dapat meningkatkan efektifiitas penggunaan perpustakaan.

Namun di tengah pesatnya perkembangan teknologi informasi yang mampu mengakses data atau informasi yang tersebut dengan cepat, efisien serta akurat, nampak kondisi umum perpustakaan justru berkebalikan. Sebagian besar perpustakaan belum menggunakan teknologi informasi dan masih menerapkan sistem basis data manual yang semua proses transaksinya ditulis pada kertas. Tentu saja penggunaan sistem basis data manual tersebut dalam pengaksesan data atau informasinya akan lambat, kurang efisien bahkan data atau informasi belum tentu terjamin akurasinya.
Demikian pula dengan permasalahan yang timbul dalam sistem informasi perpustakaan SMK Negeri 4 Banjarmasin, selama ini perpustakaan SMK Negeri 4 Banjarmasin masih menggunakan database manual yang semua proses transaksinya ditulis pada kertas. Hal ini diperoleh dari hasil pengamatan dan beberapa siswa SMK Negeri 4 Banjarmasin. Hasil analisis peneliti terhadap sistem informasi perpustakaan SMK Negeri 4 Banjarmasin ditemukan bahwa :

a. Daftar koleksi buku masih dituliskan dalam kertas sehingga susah untuk mensortir dan mengelola daftar koleksi buku tersebut.

b. Pengecekkan ketersediaan buku tidak bisa dilakukan.

c. Pencatatan peminjaman dan pengembalian buku sering terjadi kesalahan penulisan sehingga membuat operasional perpustakaan menjadi lambat.

d. Format penulisan data kadang tidak sama antara petugas perpustakaan satu dengan petgas perpustakaan yang lain.

e. Siswa sering terlambat dalam pengembalian buku karena faktor lupa.

f. Perhitungan biaya denda keterlambatan pengembalian buku masih dilakukan secara manual. 
Berdasarkan pada permasalahan di atas, maka diperlukan adanya aplikasi perpustakaan yang dapat mendukung pengolahan data anggota, data peminjaman dan pengembalian buku, perhitungan transaksi pembayaran denda keeterlambatan pengembalian buku pencarian buku yang dibutuhkan dengan aplikasi perpustakan yang terkomputerisasi ini, diharapkan dapat menambah nilai guna terhadap perpustakaan di SMK Negeri 4 Banjarmasin, terutama bagi petugas perpustakaan dalam pengolahan data transaksi yang terjadi pengelolaan data anggota, peminjaman koleksi, pengembalian koleksi serta pengingat jadwal pengembalian buku sehingga sirkulasi peminjaman buku dapat lebih efektif.

\subsection{Rumusan Masalah}

Masalah yang dibahas dalam penelitian yang akan dilakukan berdasarkan latar belakang masalah diatas adalah :

a. Bagaimana membuat aplikasi perpustakan yang dapat digunakan untuk pengolahan data anggota, data peminjaman dan pengembalian buku, perhitungan transaksi pembayaran denda keterlambatan pengembalian buku, pencarian buku yang dibutuhkan.

b. Bagaimana membuat aplikasi yang memberikan informasi tentang koleksi buku perpustakaan yang ada dan yang terbaru.

\subsection{Batasan Masalah}

Adapun batasan masalah dalam penelitian ini adalah sebagai berikut :

a. Aplikasi perpustakaan berfungsi untuk mengolah data anggota, data peminjaman dan pengembalian buku, perhitungan transaksi pembayaran denda keterlambatan pengembalian buku, pencarian buku yang dibutuhkan.

b. Aplikasi yang dibuat merupakan aplikasi administrasi perpustakaan

\subsection{Tujuan Penelitian} adalah :

Tujuan yang ingin dicapai dalam penelitian ini

a. Membuat sistem informasi perpustakaan yang dapat digunakan untuk pengolahan data anggota, data peminjaman dan pengembalian buku, perhitungan transaksi pembayaran denda keterlambatan pengembalian buku, pencarian buku yang dibutuhkan.

\subsection{Manfaat Penelitian}

Manfaat yang ingin dicapai dalam penelitian ini adalah :

a. Manfaat teoritis

Hasil penelitian ini dapat digunakan sebagai berikut :

1) Bahan kajian dalam meningkatkan kualitas suatu rancang bangun aplikasi perpustakaan

2) Sumbangan wawasan dan pengetahuan mengenai rancang bangun aplikasi perpustakaan

b. Manfaat praktis

1) Bagi siswa

a) Memberi kemudahan bagi siswa dalam peminjaman dan pengembalian buku

b) Mempermudah akses informasi tentang koleksi buku yang ada di perpustakkan

2) Bagi guru

a) Mengatasi kesulitan dalam pengelolaan data perpustakaan

b) Sirkulasi peminjaman buku lebih efektif sehingga dapat meningkatkan pembelajaran siswa

3) Bagi peneliti

a) Mengaplikasikan teori yang diperoleh : Menambah pengalaman peneliti dalam penelitian yang terkait dengan rancang bangun aplikasi perpustakaan.

\section{METODELOGI PENELITAN}

\subsection{Tinjauan Umum}

SMK Negeri 4 Banjarmasin merupakan salah satu dari 5 buah sekolah kejuruan di kota Banjarmasin yang telah memiliki lebih dari 900 orang siswa dengan 40 buah ruang belajar selain lab dan ruang lainnya.

SMK Negeri 4 Banjarmasin telah memiliki 6 program keahlian yaitu Tata Busana,Akomodasi Perhotelan, Tata Kecantikan, Tata Boga, Usaha Perjalanan Parawisata, dan Rekayasa Perangkat Lunak . Kemudian akan dibuka lagi program keahlian Musik. 


\subsection{Analisa Sistem Berjalan}

Analisis sistem digunakan sebagai acuan dalam tahapan pembuatan program atau aplikasi sehingga pemrograma dapat dibuat dengan lebih terencana dan terarah serta program atau aplikasi layak untuk dibuat dan diimplementasikan.

\subsection{Analisa Kelemahan Sistem}

Tujuan utama analisis sistem ini adalah untuk mengevaluasi dan menentukan permasalahan yang dihadapi, dalam hal ini sistem sirkulasi perpustakaan SMK N 4 Banjarmasin yang bertujuan agar analisis tersebut dapat diketahui permasalahan yang berkaitan dengan perkembangan organisasi dan juga untuk mengetahui kelemahan yang ada pada sistem baru. Analisis kelemahan system ini menggunakan analisis PIECES (Performance, Information, Economy, Control, Effisiency, Services)

\subsection{Analisa Kelayakan Sistem}

Studi kelayakan merupakan proses mempelajari dan menganalisis masalah yang telah ditentukan sesuai dengan tujuan akhir yang harus dicapai. Tujuan utama dari analisis kelayakan adalah untuk menguji apakah sistem baru yang akan diterapkan sebagai pengembangan dari sistem yang lama layak pakai atau tidak. Dalam tahap ini tentunya diperlukan pertimbangan yang sangat matang ketika menentukan seberapa banyak keuntungan yang didapat dan biaya yang diperlukan dari sistem baru tersebut. Sasaran yang akan dicapai dan kondisi lembaga menjadi pertimbangan utama dalam pembuatan sistem baru ini. Beberapa analisis yang digunakan untuk menguji sistem baru ini adalah : Teknologi, Hukum, dan Operasiona

\subsection{Diagram Conteks}

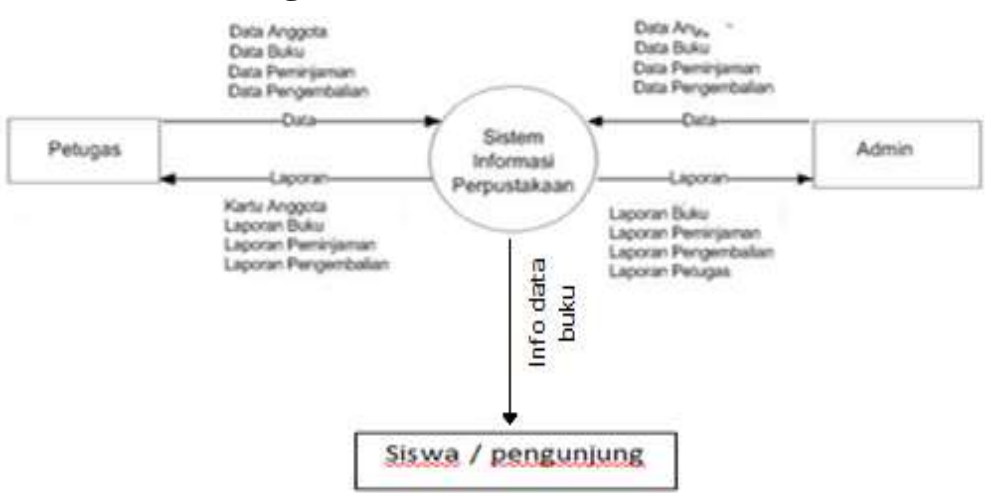

Gambar 2.1 Diagram Conteks

\section{Diagram Flow Pencarian}

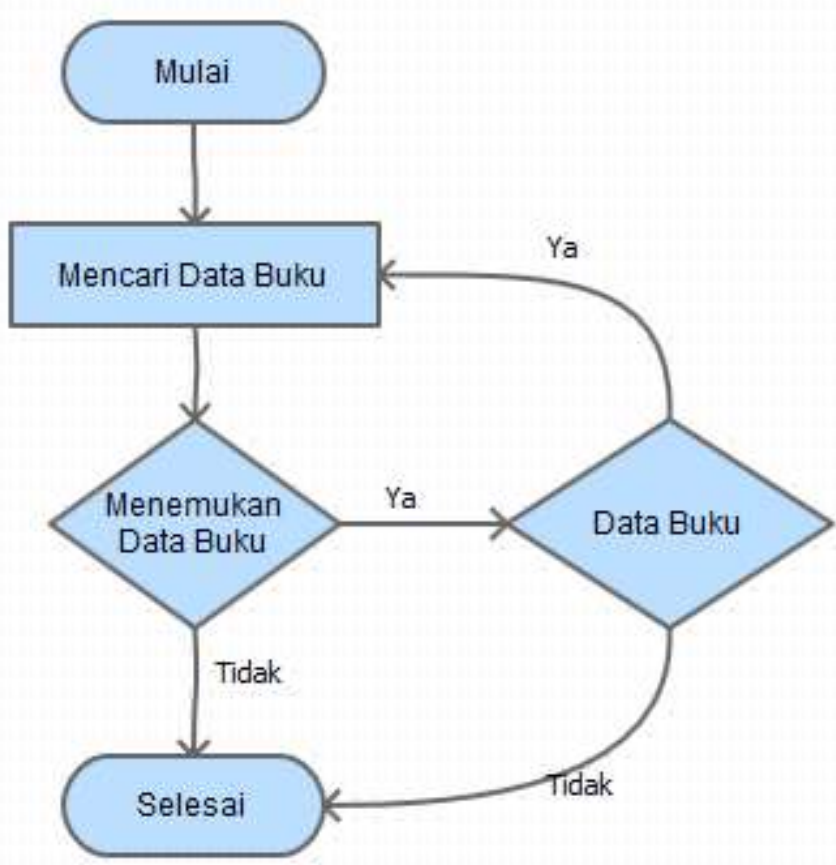

Gambar 2.2 Diagram Flow Pencarian

\section{Diagram Flow Peminjaman}

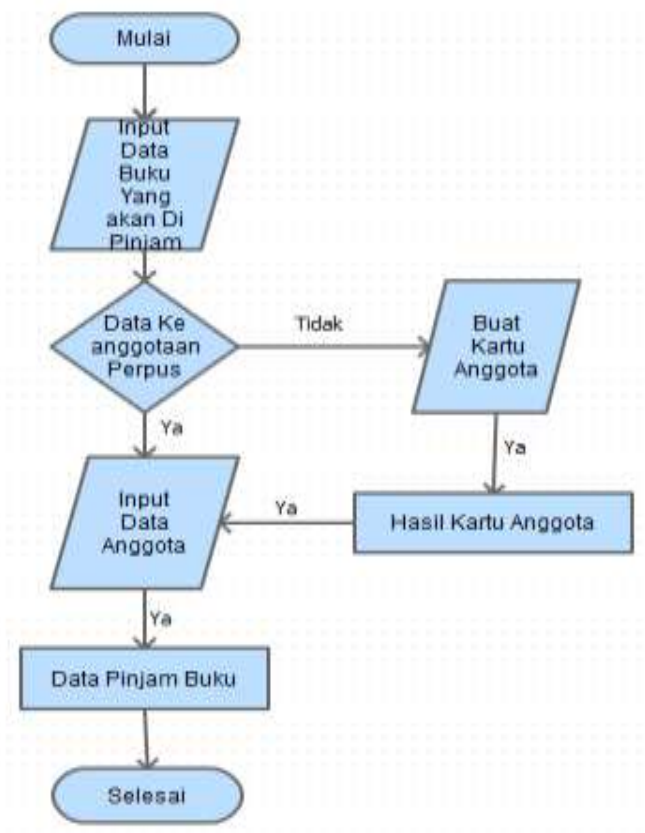

Gambar 2.3 Diagram Flow Pinjaman 


\section{Diagram Flow Pengembalian}

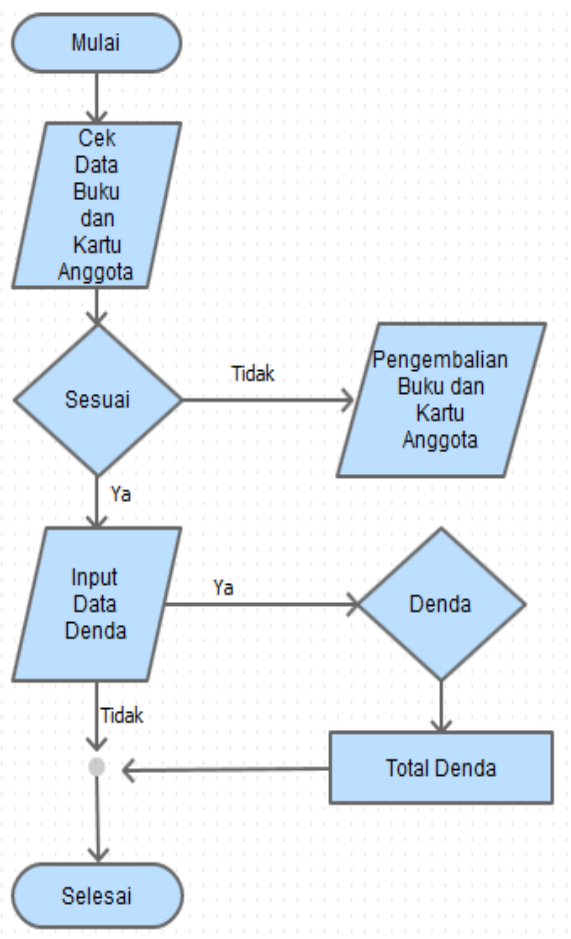

Gambar 2.4 Diagram Flow Pengembalian

\subsection{Struktur Data}

Struktur tabel yang akan dibuat dalam rancangan sistem ini dan digunakan sebagai kesatuan dalam struktur database.

\section{Table Admin}

Merupakan tabel yang digunakan untuk menyimpan data admin yaitu guru mata pelajaran. Strukturnya sebagai berikut :

Table.1 Admin

\begin{tabular}{|l|l|l|l|}
\hline Nama Field & Tipe Data & Lebar Data & Kunci(key) \\
\hline Id_admin & Int & 5 & Primary Key \\
\hline Nama & Varchar & 25 & \\
\hline Username & Varchar & 20 & \\
\hline Password & Varchar & 15 & \\
\hline
\end{tabular}

Keterangan:

a. Id_admin merupakan kode untuk setiap admin dalam aplikasi. Agar terisi dengan otomatis maka property auto_increment harus diaktifkan. b. Username dan password digunakan guru untuk login

\section{Table Siswa}

Merupakan tabel yang digunakan untuk menyimpan data siswa. Strukturnya adalah sebagai berikut:

Table. 2 siswa

\begin{tabular}{|l|l|l|l|}
\hline Nama Field & Tipe Data & Lebar Data & Kunci (key) \\
\hline Id_siswa & Int & 10 & Primary Key \\
\hline NISN & Number & 10 & \\
\hline Password & Varchar & 15 & \\
\hline Nama & Varchar & 25 & \\
\hline Kelas & Enum & & \\
\hline Jurusan & Enum & & \\
\hline Status & Enum & & \\
\hline Keteranon & & & \\
\hline
\end{tabular}

Keterangan:

a. Id_siswa merupakan kode untuk setiap siswa yang terdaftar dalam aplikasi. Agar terisi dengan otomatis maka property auto_increment harus diaktifkan.

b. Kelas disini tipe datanya enum diisi dengan pilihan X, XI, dan XII

c. Program Keahlian diisi dengan pilihan: - UPW (Usaha Perjalanan Wisata)

- Hotel (Usaha Akomodasi Perhotelan)

- Busana (Tata Busana)

- Kecantikan (Tata Kecantikan)

- Boga (Tata Boga)

- Rpl (Rekayasa Perangkat Lunak)

d. Status diisi dengan pilihan aktif atau lulus.

3. Table Guru

Merupakan tabel yang digunakan untuk menyimpan data Guru. Strukturnya adalah sebagai berikut:

Table.3 Guru

\begin{tabular}{|l|l|l|l|}
\hline \multicolumn{1}{|c|}{ Nama Field } & Tipe Data & Lebar Data & kunci \\
\hline Id_guru & Int & 10 & Primary Key \\
\hline Nip & Number & 15 & \\
\hline Password & Varchat & 15 & \\
\hline Nama & Varchat & 25 & \\
\hline Guru & Enum & & \\
\hline Status & Enum & & \\
\hline
\end{tabular}


Keterangan:

a. Id_Guru merupakan kode untuk setiap guru yang terdaftar dalam aplikasi. Agar terisi dengan otomatis maka property auto_increment harus diaktifkan.

b. Guru disini tipe datanya enum diisi dengan pilihan Umum, Normatif, Adatif dan Produktif

c. Status diisi dengan pilihan Tetap atau Honor

\section{Table Buku}

Merupakan tabel yang digunakan untuk menyimpan data siswa. Strukturnya adalah sebagai berikut:

Table.4 Buku

\begin{tabular}{|l|l|l|l|}
\hline \multicolumn{1}{|c|}{ Nama Field } & Tipe Data & \multicolumn{1}{c|}{ Lebar Data } & \multicolumn{1}{c|}{ kunci } \\
\hline Isbn & int & 20 & Primeri Key \\
\hline Judul & varchar & 50 & \\
\hline Pengarang & varchar & 25 & \\
\hline Penerbit & varchar & 20 & \\
\hline Tahun_Terbit & varchar & 10 & \\
\hline Stok & int & 11 & \\
\hline Sinopsis & text & & \\
\hline
\end{tabular}

Keterangan:

a. ISBN merupakan kode untuk setiap petugas yang terdaftar dalam aplikasi. Agar terisi dengan otomatis maka property auto_increment harus diaktifkan.

b. Stok disini tipe datanya Int diisi dengan otomatis

c. Sinopsis diisi dengang kode untuk diisis oleh petugas

5.Table Peminjam

Merupakan tabel yang digunakan untuk menyimpan data Pinjam. Strukturnya adalah sebagai berikut:

Table.5 Pinjam

\begin{tabular}{|l|l|r|l|}
\hline \multicolumn{1}{|c|}{ Nama Field } & \multicolumn{1}{c|}{ Tipe Data } & \multicolumn{1}{c|}{ Lebar Data } & \multicolumn{1}{c|}{ kunci } \\
\hline Id_anggota & varcahar & 20 & Primery Key \\
\hline Isbn & varcahar & 20 & \\
\hline Tanggal_Pinjam & Date & & \\
\hline Tanggal_kembali & & & \\
\hline Tanggal_Diterima & & 11 & \\
\hline Denda & Int & & \\
\hline Ket & Text & & \\
\hline
\end{tabular}

Keterangan:

a. Denda merupakan kode untuk setiap pengembalian yang terdaftar dalam aplikasi. Agar terisi dengan otomatis maka property auto_increment harus diaktifkan.

b. Ket diisi dengang kode untuk diisis oleh petugas terkai dengan kondisi buku

\section{Table Petugas}

Merupakan tabel yang digunakan untuk menyimpan data Petugas. Strukturnya adalah sebagai berikut:

Table.6 Petugas

\begin{tabular}{|l|l|r|r|}
\hline \multicolumn{1}{|c|}{ Nama Field } & Tipe Data & \multicolumn{1}{c|}{ Lebar Data } & kunci \\
\hline Id_Staf & Varchar & 16 & Primeri Key \\
\hline Nama & Varchar & 25 & \\
\hline Alamat & Varchar & 50 & \\
\hline Telpon & Varchar & 16 & \\
\hline Ket & Text & & \\
\hline
\end{tabular}

7.Table Anggota

Merupakan tabel yang digunakan untuk menyimpan data Anggota. Strukturnya adalah sebagai berikut:

Table.7 Anggota

\begin{tabular}{|c|c|c|c|}
\hline Nama field & Tipe Data & Lebar Data & Kunci \\
\hline Id_anggota & Varchar & 16 & Primery Key \\
\hline nama & Varchar & 25 & \\
\hline User name & Varchar & 50 & \\
\hline passwoerd & Varchar & 16 & \\
\hline
\end{tabular}




\section{Hasil Dan Pembahasan Program}

\subsection{Implementasi Pembuatan Database}

Pada pembuatan database mengunakan MySQL untuk menyimpan record infomasi, dengan mengunakan sintaks-sintaks SQL. Adapun perintah-perintah umum

SQL sebagai berikut: Create database nama_database ; Sintaks ini digunakan untuk membuat database, sedangkan dalam membuat table adalah create table nama tabel

(nama field_tipe_data(ukuran)).

\subsection{Implementasi Pengujian Sistem}

Uji coba program atau testing adalah sebuah proses terhadap program atau aplikasi untuk menemukan kesalahan dan segala kemungkinan yang akan menimbulkan kesalahan sesuai dengan spesifikasi software yang telah ditentukan sebelum aplikasi tersebut digunakan. Metode testing ada dua, antara lain :

\section{A. Black Box Testing}

Pengujian yang dilakukan untuk
antarmuka perangkat lunak. Pengujian ini dilakukan untuk memperlihatkan bahwa fungsifungsi bekerja dengan baik dalam arti masukan yang diterima dengan benar dan keluaran yang dihasilkan benar-benar tepat, pengintegrasian dari eksternal data berjalan dengan baik. Salah satu bentuk Black Box testing adalah testing validasi. Testing ini dinyatakan berhasil jika fungsi-fungsi yang ada pada perangkat lunak sesuai dengan apa yang diharapkan. Contoh testing validasi, Saat proses input data buku diwajibkan untuk mengisi field-field pada form data buku. Jika salah satu field terpenting dikosongkan, maka akan muncul pesan informasi kesalahan. Berikut contoh tampilannya.

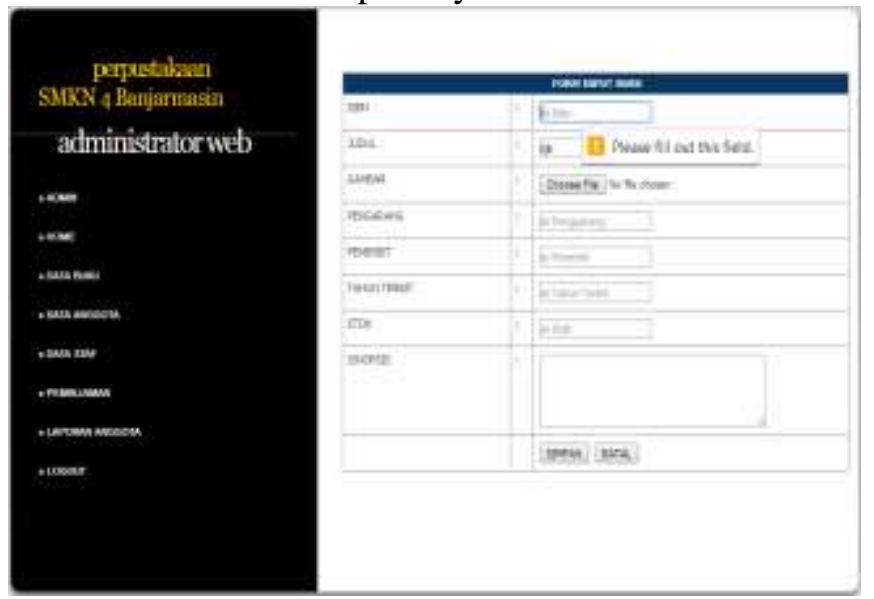

Gambar 3.1 testing validasi

\section{B. White Box Testing}

Pengujian yang dilakukan lebih dekat lagi untuk menguji prosedur-prosedur yang ada. Lintasan logik yang dilalui oleh setiap bagian prosedur diuji dengan memberikan kondisi yang spesifik. Salah satu contoh white box testing ialah saat login admin dan jika data yang dinputkan tidak sesuai atau kosong maka admin tidak bisa login. Untuk mengatasi hal tersebut maka perlu dibuat validasi ada beberapa kondisi didalam program yang menentukan layak atau tidaknya validasi data pada kolom tersebut. Berikut contoh programnya:

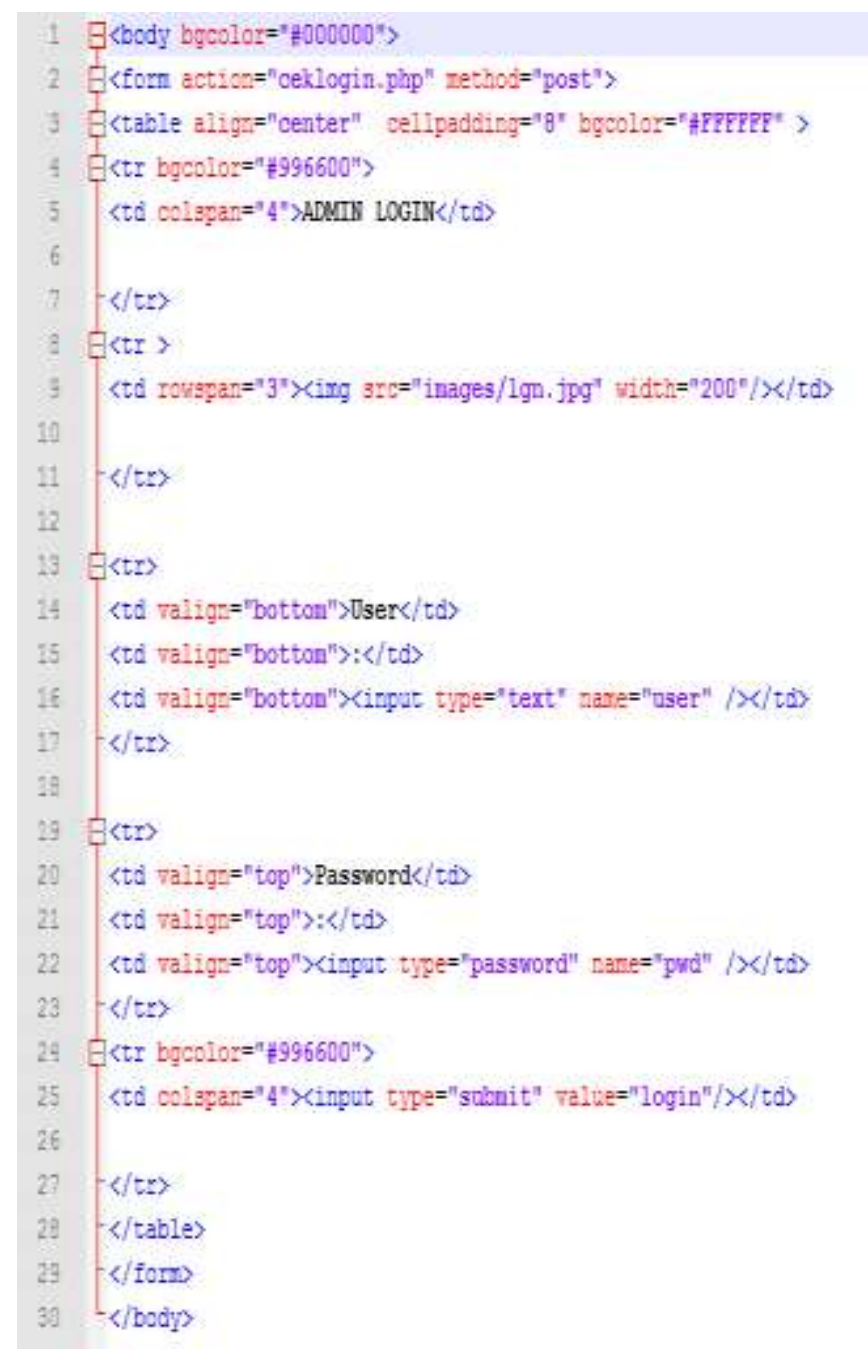

Gambar 3.2 Contoh White Box 


\subsection{Cara Pengoperasian Aplikasi Perpustakaan}

Setelah semua kebutuhan yang diperlukan dipenuhi, langkah selanjutnya adalah menjalankan aplikasi Perpustakaan. Saat pertama kali dijalankan, aplikasi akan memeriksa apakah database sudah dibuat atau sudah belum, jika belum maka aplikasi akan memberitahu bahwa login gagal tapi jika data sudah dibuat didatabase maka aplikasi akan memberitahu bahwa login sukses.

\section{KESIMPULAN}

Berdasarkan hasil penelitian dengan Judul “ Sistem Informasi Perpustakaan Berbasis Web Pada SMK Negeri 4 Banjarmasin”, maka dapat diambil kesimpulan sebagai berikut :

a. Sistem Informasi Perpustakaan Berbasis Web Pada SMK Negeri 4 Banjarmasin dapat digunakan untuk mepermudah anggota mengetahui semua koleksi buku yang tersedia pada perpustakaan.

b. Sistem Informasi Perpustakaan Berbasis Web Pada SMK Negeri 4 Banjarmasin dapat menghemat waktu bagi anggota dalam SARAN mencari koleksi buku yang tersedia.

Pengembangan Sistem Informasi Perpustakaan Berbasis Web Pada SMK Negeri 4 Banjarmasin masih terdapat kekurangan, oleh karena itu perlu pengembangan lebih lanjut agar sistem ini lebih bermanfaat. Adapun untuk peneliti selanjutnya ada beberapa hal yang disarankan :

1. Sistem Informasi Perpustakaan Berbasis Web Pada SMK Negeri 4 Banjarmasin tidak bisa diakses di hp oleh karena itu disarankan untuk pengembangan sistem ini bisa dikembangkan ke web mobile.

\section{DAFTAR PUSTAKA}

Depdikbud, 1996, Periodisasi Perpustakaan Indonesia, PT Puri Pustaka, Bandung

Fathansyah, 1999, Basis Data, Informatika, Bandung

Unknown, 1990, Analisis dan Disain Sistem Informasi Pendekatan Terstruktur Teori dan Praktek Aplikasi Bisnis, Andi, Yogyakarta

Unknown, 2004, Aplikasi Program PHP dan MySQL, Andi dan Madcoms

Jasmadi, 2004, Koleksi Template Web dan Teknik Pembuatannya, Andi Offset, Yogyakarta

Kadir Abdul, 2002, Penuntun Praktis Belajar SQL, Andi, Yogyakarta

Unknown, 2003, Pengenalan Sistem Informasi, Andi, Yogyakarta
Kristanto Andri, 2004, Rekayasa Perangkat Lunak (Konsep Dasar), Gava Media, Yogyakarta

Pramono Andi, Syafii. M, 2005, Kolaborasi Flash, Dreamweaver dan PHP untuk Aplikasi Website, Andi Offset, Yogyakarta

Sunarfrihantono Bimo, 2002, PHP dan MySQL untuk Web, Andi Offset, Yogyakarta

SyahPutra Andry, 2003, Apache Web Server, Andi Offset, Yogyakarta

Unknown, Membuat Website Interaktif dengan Macromedia Dreamweaver MX, Andi Offset, Yogyakarta

Priyanto Adi Wahyu, 2011, Analisa Dan Perancangan Aplikasi Perpustakaan Sekolah Berbasis Web Di SMK Negeri 3 Pekalongan, .........., Yogyakarta 